\title{
Correlações entre pesquisa-ação e práxis pedagógica freireana: Uma educação dialógica a partir do contexto cultural
}

\author{
Lilian Maria Moser \\ Orcid: https://orcid.org/0000-0003-0574-2743 \\ Hualan Patrício Pacheco ${ }^{2}$ \\ Orcid: https://orcid.org/0000-0002-8837-2647 \\ Eduardo Servo Ernesto ${ }^{3}$ \\ Orcid: https://orcid.org/0000-0002-9804-6968
}

\begin{abstract}
Resumo
O presente trabalho tem como objetivo propor correlações entre pesquisa-ação e o método de alfabetização de Paulo Freire (2019a). Nesse viés, discutimos sobre a pesquisa-ação com vistas à produção de novos conhecimentos em ciências humanas a partir da resolução de problemas sociais em diálogo com a práxis pedagógica freireana, vislumbrando-se, no campo da Educação, pesquisas que possam viabilizar cooperação entre sujeitos. O método de Paulo Freire é visto quanto aos processos de ensino e aprendizagem, à alfabetização e/ou escolarização das classes populares tendo nos temas geradores junto aos aspectos culturais pontos de convergências epistemológicas à pesquisa-ação. Nesse sentido, interessam os questionamentos e a dialogicidade dos problemas e/ou situações dos cotidianos. Em termos metodológicos, recorreu-se a materiais bibliográficos para a concatenação das ideias-chave de Freire e destaca-se que a pesquisa-ação apresenta estreito debate com o método de Freire, bem como sobre a relação do pesquisador/professor e o público da pesquisa que torna este método uma ação de cooperação e promoção de conhecimentos com vistas a solucionar problemas sociais.
\end{abstract}

Palavras-chave: Método da Pesquisa-ação. Método de Paulo Freire. Educação. Ensino.

\begin{abstract}
The presente work aims to reflect on possible correlations between the action research method and Paulo Freire's pedagogical proposal. In this way, we conceptualize and discuss action research with a view to producing new knowledge in the humanities from the resolution of social problems envisioned in the field of educational research through cooperation between subjects involved in this movement. Paulo Freire's method is applied to the literacy of those belonging to popular classes in which cultural aspects are placed in vogue in the questioning and dialogicity of everyday problems and situations. The methodology applied in this research was the bibliographic review, in which Freire's writings were put in complement to those that are basic in the construction of the concept of action research. At the end of the work, we observed that even though the Freire method is totally related to the participatory research method, the inclinations to the action research method are also part of the teaching process described and created in northeastern Brazil. The most important aspect that converges in the
\end{abstract}

\footnotetext{
${ }^{1}$ Possui graduação em História pela Universidade Federal de Rondônia (1992) e doutorado em Desenv. Sustentável (UFPA, 2006). Professora do Departamento de História e da Pós-Graduação em História da Amazônia da Universidade Federal de Rondônia, cidade de Porto Velho, RO. E-mail: Lilian.msr@gmail.com

${ }^{2}$ Doutorando pelo Programa de Pós-Graduação em Educação Escolar (UNIR). Licenciado em Física (2012). Professor EBTT

-IFRO, campus da cidade de Porto Velho, RO. E-mail: hualan.pacheco@ifro.edu.br

${ }^{3}$ Doutorando pelo Programa de Pós-Graduação em Educação Escolar (UNIR). Graduado em História (2011). Professor de História pela Prefeitura do município de Porto Velho, RO. E-mail: eduardoernesto1010@gmail.com.
} 
direction of action research, related to the Freire method is the relationship between the researcher / teacher and the research public, in this case the relationship of cooperation and knowledge of the locality is an integral part of the actions of those involved.

Keywords: Action Research Method. Paulo Freire's method. Education. Teaching

\section{Introdução}

Este trabalho tem como objetivo a discussão sobre a temática de pesquisa-ação que questiona os modelos pré-estabelecidos e impostos pelos paradigmas de homogeneização da modernidade, cujo conhecimento construído desvaloriza os grupos sociais, seu modo de pensar, viver e de organizar seu cotidiano e suas práticas consolidadas num cenário considerado não científico pelo modelo tradicional da ciência. Discutimos esses pontos de críticas epistêmicas realizadas a partir da pesquisa-ação correlacionadas com aspectos da proposta pedagógica freireana visando a produção de conhecimento que não aliene, não hierarquize práticas e saberes e abram horizontes para outros olhares sobre a educação.

Para a construção da argumentação deste trabalho, partimos das leituras de Barbier (2004), que destaca a pesquisa-ação com sua origem no decorrer da Segunda Guerra Mundial (1939 - 1945), no momento em que psicólogos, sociólogos e outros cientistas sociais buscavam uma metodologia que atendesse aos anseios dos pesquisadores envolvidos com os contextos sociais. Por muito tempo foi possível observar a aplicação da pesquisa tradicional e de seus métodos de maneira extensa em diversas áreas, mesmo naqueles cenários em que o pesquisador e o campo de pesquisa têm relações bem estreitas, não sendo possível a separação desses dois objetos.

O surgimento de uma concepção de pesquisa-ação deve-se ao psicólogo, naturalizado nos Estados Unidos, Kurt Lewin que realizou pesquisas no seu campo de estudo e permitiu com que diversas vertentes de seu método fossem criadas. No entanto, a ideia central sempre se manteve: a participação de pesquisadores e pesquisados para, em conjunto, solucionar problemas presentes no campo de pesquisa gerando conhecimento novo.

O método de pesquisa-ação é relativamente recente em comparação com outros métodos quantitativos derivados das Ciências Naturais que possuem grande aplicação de coeficientes de correlação e, consequentemente, outras variáveis da Estatística e Probabilidade para a explicação dos fenômenos e situações. No entanto, o direcionamento de pesquisas educacionais para pequenos públicos, localidades distantes e a necessidade de envolver os atores ou comunidades com foco na resolução desses problemas locais permitiu com que o método de pesquisa-ação se tornasse imprescindível.

Neste estudo, a pesquisa-ação enquanto método é abordada a partir de Thiollent (1986) e Barbier (2004), que apresentam importantes conceitos e, de algum modo, apontam para a necessidade de ruptura epistemológica, seja na forma de se pensar a investigação qualitativa, seja no formato de pensar a pesquisa em educação como movimento bidimensional, em que pesquisador e atores locais podem estabelecer resolução de problemáticas sociais.

Ao tratarmos do cenário social em suas diversas dimensões, podemos observar o método de Paulo Freire ${ }^{4}$ (2019a) não somente como uma proposta de alfabetização e/ou escolarização,

\footnotetext{
${ }^{4}$ Paulo Freire nunca defendeu um método rígido de educação como se esse fosse apenas a aplicação de técnicas de alfabetização. Ao contrário, Freire (2019c) defendeu a existência de várias formas de ensinar. Nas palavras de Brandão (1981) o método de Paulo Freire é estabelecido de forma dialógica a partir de uma relação horizontal entre educandos e educador, tendo nas dimensões práticas da vida, local comum de no qual emergem os temas geradores e os chamados círculos de cultura, como forma de transgredir uma educação bancária reprodutora da ordem socioeconômica vigente. Aprofundando essa proposta, em um primeiro momento, com a ajuda de uma pessoa alfabetizada, são realizadas atividades que visavam obter um conhecimento do universo vocabular e temático do grupo a ser alfabetizado. Em um segundo momento, a partir do levantamento temático, os círculos de cultura incentivam os componentes do grupo a elaborarem investigações sobre seu universo vocabular, realizando sua aprendizagem a partir do local comum que ocupam no mundo.
} 
mas também como um método de pesquisa participante ${ }^{5}$, que vê no contexto cultural de grupos populares os aspectos necessários para a educação dialógica.

A cultura e sua implicação para o homem popular ${ }^{6}$ foi tema presente em diversas obras de Freire (2019a, 2019b, 2019c, 2020) e de sua práxis $^{7}$ ao longo dos anos, partindo da atuação nos círculos/centros de cultura de Recife e que culminaram com a concepção do método de alfabetização até a difusão, atuação e a construção de ativismo nas lutas pelos interesses das classes populares.

A busca por palavras do universo vocabular do aluno, para, a partir de então realizar a alfabetização do povo, do popular, do operário, do oprimido não é o único ponto de enaltecimento do método desenvolvido por Freire (2019a).

Podemos realizar o questionamento sobre quais os aspectos que permitiram com que resultados tão inovadores pudessem ser alcançados e as contribuições do método de Paulo Freire para educação e sua implicação para o contexto educacional nacional levando em conta a repercussão positiva sobre o método. Seguimos na tentativa de realizar as enunciações para este aspecto.

Podemos então destacar os diálogos entre pesquisador/educador e o povo na busca por um universo vocabular que expressa não somente essa característica, mas as concepções de mundo daqueles que serão alfabetizados e que é tão relevante para situar o pesquisador, ou ainda o docente dentro do contexto de cada aluno.

A questão da linguagem, no fundo, uma questão de classe é igualmente outro ponto em que pode emperrar a prática educativa progressista. Um educador progressista que não seja sensível à linguagem popular, que não busque intimidade com o uso de metáforas e parábolas no meio popular, não pode comunicar-se com os educandos, perde a eficiência, é incompetente (FREIRE, 2020, p. 64).

É possível também situar o método de Freire no contexto humanístico, em que temos reveladas muito mais nuances do que o próprio método de ensino e de alfabetização aplicado com tanta maestria. Observa-se também a evidência do posicionamento do docente com relação ao público-alvo de sua prática: "com o povo, nunca apenas para ele ou sobre ele" (FREIRE, 2019a, p.78).

Todos estes aspectos estão relacionados a uma proposta de enfoque para a educação da época de transição e concepção do método de Freire, com democratização e classes sociais emergindo ao cenário político, sendo por fim notadas por diversos setores sociais, embora com

\footnotetext{
${ }^{5}$ Entendemos aqui pesquisa participante como um método de investigação na qual existe uma ação que visa à geração de conhecimentos a partir de uma relação horizontal entre pesquisador e atores envolvidos na resolução de problemas sociais (THIOLLENT,1986). É desse envolvimento e cooperação coletiva horizontal que pensamos existir uma correlação com a práxis pedagógica freireana quando o imbricamento entre sujeitos gera a produção de conhecimentos que não hegemonizam o processo na figura do professor/pesquisador e esse movimento dialógico gera a possibilidade de experienciar o mundo a partir do local do outro.

${ }^{6}$ Homem popular é o membro das classes populares que através do trabalho busca o sustento de sua família (agricultor, operário, construtor civil e tantas outras profissões). São aqueles que se encontram na margem social e em muitos casos desassistidos pelo poder público e suas ações de integração e alavancamento social, são os marginalizados.

${ }^{7}$ Práxis pode ser definida na proposta pedagógica freireana como uma relação intrínseca entre teoria e as dimensões práticas da vida em um movimento que visa interpretar a realidade tendo como consequência uma ação transformadora que objetiva a emancipação de sujeitos. Em outras palavras, teoria e prática são faces de uma mesma moeda que busca estabelecer uma relação crítica da realidade social experienciada/compartilhada por sujeitos em um movimento que visa transgredir uma educação que reproduz uma sociedade alienada aos interesses dominantes, autoritária e que suprime a condição de humanidade de seres humanos. Nas palavras de Paulo Freire: "Agora, nenhuma, separação entre pensamento-linguagem e realidade" (FREIRE, 1978, p.70), daí que a leitura de um texto demande a "leitura" do contexto social a que se refere Freire (1978) fica claro que a dimensão das práxis está diretamente correlacionada a um movimento transformador que não hegemoniza quadros teóricos, ao contrário, emerge e está intrinsicamente ligado às dimensões práticas da vida.
} 
enfoques diversos. As ações de Freire e outros pesquisadores que atuavam nos círculos/centros de cultura convergiam no sentido de:

Tentar uma educação que fosse capaz de colaborar com ele na indispensável organização reflexiva de seu pensamento. Educação que pusesse à disposição meios com os quais se fosse capaz de superar a captação mágica ou ingênua de sua realidade dominantemente crítica, isso significava então colaborar com ele, um pouco, para que assumisse posições cada vez mais identificadas confirmando a dinâmica da fase de transição (FREIRE, 2019a, p. 139).

Os desenvolvimentos do método, por meio do debate sobre as palavras geradoras, permitem que o educando se reconheça como pertencente a uma classe, um meio social, como povo ao invés de massa.

O contexto cultural, tanto na concepção de um currículo quanto na questão histórica de sala de aula, é de grande importância. Nesse sentido, o debate pode se estender a outros autores, e, dentre estes, se destaca Candau:

\begin{abstract}
Não há educação que não esteja imersa nos processos culturais do contexto em que se situa. Nesse sentido, não é impossível conceber uma experiência pedagógica 'desculturalizada', isto é, desvinculada totalmente das questões culturais da sociedade. Existe uma relação intrínseca entre educação e cultura(s). Esses universos estão profundamente entrelaçados e não podem ser analisados a não ser a partir de sua íntima articulação (CANDAU, 2008, p. 13).
\end{abstract}

A escola está inserida em um contexto social e por essa razão a consideração dos hábitos e costumes existentes na comunidade é ponto essencial para a construção de práticas pedagógicas e discussões didáticas sobre essas práticas. A instituição escolar é um espaço em que ocorrem os cruzamentos de culturas, que são complexos, estão completamente carregados de tensões e até conflitos. Vale considerar que a educação de cunho progressista também deve levar em conta estes aspectos e transpor os entraves para uma convivência que não negue o outro, que, ao dizer de Freire (2019c), não negue a possibilidade de humanos exercerem sua humanidade no mundo, almejando um convívio em que as diferenças culturais não sejam vistas como negativas e passíveis de serem superadas, que de igual modo é destacado por Candau (2008).

Percebemos uma convergência dessa fala de Candau (2008) com o termo "invasão cultural" adotado por Paulo Freire (2019c, p. 119) na elaboração de currículos e práticas pedagógicas nas dimensões práticas da atuação docente e na própria noção de escola. Essas instituições se configuram, em muitas oportunidades, como locais homogeneizadores, pois se configuram como ceifadoras das singularidades e subjetividades de indivíduos que compartilham comportamentos e saberes distintos dos "oficializados como corretos" nas falas de professores que não problematizam suas práticas e conteúdos dos livros didáticos.

Aprofundando esse raciocínio, pode-se sintetizar que Paulo Freire (2019c) compreende invasão cultural como a eleição de determinados valores estéticos, éticos e pedagógicos como hegemônicos, e a imposição desses de forma autoritária no ambiente escolar, que acabam homogeneizando as relações sociais e incutindo uma ideia de desvalorização cultural e social dos saberes e práticas de determinados grupos populares.

Candau (2008) e Freire (2019) consideram que, em alguns momentos, as instituições escolares acabam assumindo posições e ações que servem como aporte à desvalorização das diferenças bem como a existência do desejo em eliminá-las dos espaços escolares em nome da padronização. Percebemos essa posição pedagógica de muitas instituições e projetos escolares como a materialização da antidialogicidade, que contribui para reprodução de estereótipos, preconceitos além da manutenção da desigualdade socioeconômica em nossos dias atuais. 
Com base nisso, a partir da proposta pedagógica freireana e da pesquisa-ação, construímos neste trabalho uma proposta de pesquisa em educação menos hierarquizada e que não coloca o pesquisador no alto de um "pedestal". No viés metodológico da pesquisa-ação o pesquisador e o grupo investigado constroem, conjuntamente ou de modo cooperativo, o conhecimento dialógico e a bidimensionalidade. Evita-se o processo unilateral que hegemoniza o pesquisador acadêmico como protagonista do processo de produção de conhecimento, proposta metodológica que consequentemente apresenta fortes críticas à pesquisa tradicional que comumente compreende as práticas culturais compartilhadas nas formas de vida das camadas populares como senso comum.

\section{O que é a pesquisa-ação e a importância deste método de pesquisa para as ciências sociais}

As reflexões sobre as nomenclaturas comumente confundidas como sinônimos são relevantes, podemos refletir sobre a etimologia da palavra método e também da metodologia, o que pode nos dar um ponto de partida para a definição do que vem a ser a pesquisa-ação.

Já é conhecida a expressão que associa um professor e sua prática a uma boa ou má metodologia de ensino. Em alguns casos a palavra é trocada por método e talvez o emprego desapegado de significado reflita a apropriação de vocabulário e não o conhecimento deste com afinco e profundidade. De acordo com Oliveira (2016), podemos definir a metodologia como sendo um conjunto de técnicas necessárias para desenvolver os processos de produção de conhecimento novo, de pesquisa e de planejamento. Essa conceituação, realizada à luz do pensamento científico é a que nos interessa nesse projeto e a que provavelmente seja o cerne de toda aplicação posterior do substantivo. Assim a autora nos traz:

Entenda-se como metodologia da pesquisa um processo que se inicia desde a disposição inicial de se escolher um determinado tema para pesquisa até a análise dos dados com as recomendações para a minimização ou solução do problema pesquisado. Portanto, metodologia é um processo que engloba um conjunto de métodos e técnicas para ensinar, analisar, conhecer a realidade e produzir novos conhecimentos (OLIVEIRA, 2016, p. 43).

O debate instituído por Oliveira (2016) acima é relevante. No excerto, observamos a presença do termo método como parte integrante da metodologia. Em verdade o primeiro é um dos componentes que totalizam o segundo.

Thiollent (1986, p. 31) afirma que "a metodologia é entendida como disciplina que se relaciona com a epistemologia ou a filosofia da ciência". Conceituação que está em completo acordo com a definição anteriormente apresentada.

Oliveira (2016, p. 48) também nos entrega a definição da palavra método como sendo "o caminho escolhido para se atingir os objetivos preestabelecidos na elaboração do projeto de pesquisa". Embora existam diversas definições, de diversos autores, mais ou menos amplas do que essa, é através desse ponto de partida que podemos tecer os comentários sobre o papel da pesquisa-ação dentro do contexto da pesquisa.

Encerrada a definição de metodologia e método, podemos entender a pesquisa-ação, tal como Barbier (2004, p. 118) a concebe, explicitamente como método. Também podemos utilizar a definição de Thiollent (1986, p. 32), em que observamos:

À luz do que precede, a pesquisa-ação não é considerada como metodologia. Trata-se de um método, ou de uma estratégia de pesquisa agregando vários métodos ou técnicas de pesquisa social, com os quais se estabelece uma estrutura coletiva, participativa e ativa na captação de informação. A metodologia das ciências sociais considera a pesquisa ação como qualquer outro método. 
Alguns autores trazem reflexões bastante profundas sobre a aplicação de determinados métodos ao mesmo problema de pesquisa, um exemplo de grande impacto dentro do contexto da psicologia, é o de Vygotsky (2014). Na obra A construção do pensamento e da linguagem, tece discussão ampla sobre as investigações acerca das relações entre pensamento e linguagem, indo desde o método de análise ao método de decomposição em elementos/unidades.

A definição da pesquisa-ação pode ser encontrada em um dos clássicos sobre a pesquisaação na literatura nacional que é Thiollent (1986)

\begin{abstract}
A pesquisa-ação é um tipo de pesquisa social com base empírica que é concebida e realizada em estreita associação com uma ação ou com a resolução de um problema coletivo e no qual os pesquisadores e os participantes representativos da situação ou do problema estão envolvidos de modo cooperativo ou participativo (THIOLLENT, 1986, p. 14).
\end{abstract}

Outras referências: Barbier (2004, p. 53) faz menção ao conhecimento empírico que é atribuído ao uso da pesquisa-ação, bem como a elucidação do fato de que o aspecto prático do campo de pesquisa é mais importante que o conhecimento teórico que poderá ser gerado ao longo, e ao término, do processo.

Thiollent (1986) explicita o caráter de método dado à pesquisa-ação, bem como a sua capacidade de agregar várias ferramentas de investigação e análise, ou seja, através de vários outros métodos e técnicas de pesquisa.

Barbier (2004) debate sobre características que compõem a estratégia metodológica da pesquisa-ação, consistindo em seis passos necessários para a aplicação desta em campo, juntamente com os atores da pesquisa:

a) Existe uma ampla e explícita relação de cooperação entre as pessoas implicadas na pesquisa e os pesquisadores que atuam na situação investigada através de ações conjuntas;

b) A ordem de prioridade dos problemas a serem pesquisados é resultante da interação entre esses pares. As soluções a serem encaminhadas sob forma de ação concreta também estão influenciadas por esta interação, portanto é uma indicação dos personagens do campo de pesquisa e não do pesquisador;

c) A situação social e os problemas de diferentes naturezas é que constitui o objeto da investigação, as pessoas envolvidas no problema serão os atuantes na busca pela sua resolução;

d) O objetivo da pesquisa-ação é o de resolver, ou pelo menos esclarecer, o problema apontado por aqueles que vivenciam a situação colocada;

e) Há, durante o processo, um acompanhamento das decisões, das ações e de toda a atividade intencional dos atores da problemática. A intervenção por parte do pesquisador é analítica e participativa, tendo em vista a sua integração ao problema e situação;

f) A pesquisa-ação não se constitui de uma prática, uma ação, é tida também como uma maneira de aumentar o conhecimento dos pesquisadores e o conhecimento ou o "nível de consciência" das pessoas ou grupos pesquisados.

Os pontos acima são fundamentais para o desenvolvimento de uma pesquisa-ação, que seja real, que modifique o panorama geral das pesquisas científicas existentes, em especial aquelas de cunho social, mudando assim a ordem dominante da cientificidade.

Podemos, ao final de uma análise criteriosa e comparativa, realizar uma distinção entre a pesquisa-ação e a pesquisa tradicional, que está fundamentada em alguns pontos de Debate instituído por Barbier (2004, p. 51): 
a) A posição de valor para a pesquisa-ação é de caráter social, com vistas à liberação do potencial humano em um movimento bidimensional pesquisador e atores envolvidos, o que agrega subjetividade, historicidade e diferentes formas de ver e sentir o problema investigado;

b) A pesquisa tradicional possui métodos que são caracterizados como neutros, a fim de construir uma "interpretação da verdade" sobre um elemento social, que hegemoniza a figura do pesquisador acadêmico na produção de conhecimento. Em outras palavras, essa modalidade de pesquisa acredita que a suposta neutralidade do pesquisador munido de uma teoria, método e fonte constroem um conhecimento objetivo e verdadeiro quando respalda esse saber a partir de uma teoria no aspecto verificacionista consubstanciado pela fonte.

c) A pesquisa-ação, dentro do contexto da temporalidade, problematiza a historicidade e faz reflexões sobre o tempo presente em um movimento para o futuro que o problema social inicial seja superado; quanto a isso a pesquisa tradicional é direcionada ao tempo presente, se atendo aos acontecimentos e hegemonizando os aspectos teóricos sobre as dimensões práticas da vida e dos sujeitos participantes da pesquisa;

d) Outro aspecto interessante da pesquisa-ação está relacionado ao público, ou seja, às unidades de pesquisa, em que é tido que nessa metodologia o público-alvo são sujeitos conscientes que também constroem a pesquisa em um movimento bidimensional com o pesquisador;

e) A pesquisa tradicional trata este componente do processo como o objeto de estudo, dando ao "público-alvo" o caráter passivo no processo;

f) A utilização da Indução e dedução na pesquisa tradicional é parte primordial para o desenvolvimento dessa metodologia, já nos mesmos termos de aumento dos conhecimentos destaca-se a pesquisa-ação como baseada em "conjecturas" em que é ausente o receio em criar situações objetivando a mudança de conhecimento;

g) Por fim, quanto aos critérios de confirmação, a pesquisa tradicional traz consigo os conhecimentos embasados em uma consistência lógica, conjectura e controle, em conceitos da ciência lógica e positiva, enquanto a pesquisa-ação baseia-se na avaliação dos efeitos da ação produzida pelos pares da pesquisa.

$\mathrm{Na}$ etapa de desenvolvimento da investigação a partir da aplicação da pesquisa-ação, em contextos sociais, observa-se o engajamento e militância dos pesquisadores quando utilizados no cenário das classes populares ou dominados. Verifica-se a necessidade de um caráter social aplicado a este método de pesquisa, ou ainda um caráter político distante do conservadorismo.

Poderemos observar a implicação da pesquisa-ação nesse âmbito, em que se faz necessário que nos lembremos das palavras de Ludke e André (2020), que definem o fenômeno educacional como aquele que está situado dentro de um contexto social, inserido em uma realidade histórica que sofre toda uma série de determinações sendo, por isso, passível de ser problematizado e modificado em um movimento que implica distintos atores sociais.

Nesse sentido, pensar em uma pesquisa educacional que não leve em consideração o caráter social dos participantes, suas aspirações, suas opiniões políticas, suas ideias quanto à resolução de um problema e a historicidade de cada ser, é navegar nas águas da pesquisa tradicional.

Diante do contexto da pesquisa tradicional é preciso verificar o quanto há de desafios para a alteração dessa ordem estabelecida, motivos pelos quais a pesquisa-ação se diferencia e possamos entendê-la como elo entre o pesquisador e a comunidade científica de acordo com Luna (2011, p. 24). 
No contexto de antagonismos sociais e sua superação, pensamos que o sentido de emancipação defendido por Freire (2019a, 2019b, 2019c, 2020) possui correlações com a proposta epistémica e social da pesquisa-ação, uma vez que essa modalidade de pesquisa participante corresponde a um movimento que pode ajudar profissionais da educação básica a ressignificarem suas práticas e também a própria proposta de emancipação conjecturada na teoria freireana para os atuais caminhos e descaminhos do Brasil onde as dicotomias e tensões entre capital e trabalho continuam criando arrochos econômicos sobre as camadas assalariadas e discursos que rotulam negativamente estratégias de superação dessa realidade socioeconômica imposta por grupos políticos e civis hegemônicos, vide a utilização de ferramentas de difusão de informação em massa via smartphone que rotulam negativamente os movimentos sociais compartilhados e consumidos por uma parcela significativa das próprias camadas assalariadas.

Nesse caminho, Barbier (2004) discute sobre a atuação do pesquisador no campo e com os atores da pesquisa, ou seja, a população implicada no(s) problema(s) investigado(s), assim "A pesquisa-ação é libertadora, já que o grupo de técnicos se responsabiliza pela sua própria emancipação e se auto-organiza contra hábitos irracionais e burocráticos de coerção" (BARBIER, 2002, p. 59). Em outras palavras, a pesquisa-ação é uma possibilidade de os próprios atores identificarem uma prática como um possível problema e, na tentativa de ressignificá-la, buscam estratégias para sua superação ao enxergarem o problema inicialmente posto de uma forma distinta ao final do movimento de investigação, não deixando de ser uma possibilidade de emancipação.

Escolher a pesquisa-ação como metodologia de pesquisa a uma dada investigação não significa a utilização desta como ferramenta para camuflar-se dos métodos de pesquisa científicas, nem de suas exigências, tendo em vista o caráter metodológico que está imbricado ao processo de sua execução e extração de resultados.

\section{O método de Paulo Freire: uma ênfase no diálogo, problemáticas sociais e os temas geradores}

Em suas obras escritas ao longo de décadas, Paulo Freire nunca defendeu um método de ensino enrijecido e autoritário, mas sim progressista e libertador, havendo sempre uma correlação entre diálogos e atores envolvidos no processo de ensino como educadores, educandos e sociedade circunvizinha à escola, a partir da realidade social dos distintos atores que experienciam o processo escolar, criando, assim, temas geradores a partir das tensões sociais e culturais vividas pelo grupo. Reforçou a busca por uma sociedade que não suprima a condição de humanidade de seres humanos e que permita ao educando o alcance do ser mais.

Na obra Educação como prática de liberdade Freire (2019a) é enfatizado por meio de cinco procedimentos metodológicos, uma prática pedagógica dialógica que suscite os aspectos culturais e sociais dos contextos de discentes, são eles: I) levantamento do universo vocabular dos grupos com que trabalhará; II) escolha das palavras selecionadas do universo vocabular pesquisado; III) criação de situações existenciais típicas do grupo com que se quer trabalhar; IV) elaboração de fichas que auxiliem os coordenadores de debate no seu trabalho V) confecção de fichas com a decomposição das famílias fonêmicas correspondentes aos vocábulos geradores. Aprofundaremo-nos na argumentação dos três primeiros procedimentos, tendo em vista a sua aplicação a diversas propostas didáticas.

Os procedimentos do método Paulo Freire são progressivos e interligados. De imediato, é preciso fazer o levantamento do universo vocabular dos grupos com que trabalhará. Na sua perspectiva esse levantamento é realizado por meio de encontros informais com os moradores da área em que ocorrerá o processo de ensino e de inserção dos educandos, e nesse caso, não se fixam as atenções somente para os vocábulos que são mais falados, mas também para aqueles 
que têm uma maior carga emocional para os discentes/alfabetizandos, bem como os falares típicos.

As palavras geradoras devem emergir do campo de pesquisa, local atingido pela prática, no qual se encontra um rico universo de saberes, e não de um gabinete em que estas são tecnicamente escolhidas, pois dessa forma não ocorre o reflexo da linguagem popular dentro do objeto de estudo, já que "na sintaxe ou na organização popular do pensamento se descreve o objeto e não o seu conceito grupo" Freire (2020, p. 65). Esses aspectos são muito bem explorados na segunda fase do método.

Passemos então para a abordagem do segundo aspecto do método, ou seja, a escolha das palavras, selecionadas do universo vocabular pesquisado, em que observamos que essa ação exige a adoção de critérios específicos. Assim, a seleção das palavras que serão utilizadas para alfabetização pode ser realizada de acordo com: riqueza fonêmica, teor pragmático da palavra e dificuldades fonéticas.

Para escolher as palavras geradoras, podemos contar com o critério quantitativo elucidado por Maciel (1983), definido como semiótico, ou seja, aquele que reúne maior porcentagem possível dos critérios sintático, semântico e pragmático. Destacam-se, especialmente, os dois primeiros critérios citados acima.

\footnotetext{
Hoje, nós vemos que esses dois critérios estão contidos no critério semiótico: A melhor palavra geradora é aquela que reúne em si a maior 'percentagem' possível dos critérios sintáticos (possibilidade ou riqueza fonêmica, grau de 'dificuldade' fonêmica complexa, de 'manipulabilidade' dos conjuntos de sinais, as sílabas, etc.), semânticos (maior ou menor 'intensidade' do vínculo entre a palavra e o ser designado, maior ou menor adequação entre palavra e ser designado, etc.) o pragmático (maior ou menor teor de conscientização que a palavra traz em potencial, ou conjunto de reações socioculturais que a palavra gera na pessoa ou grupo que a utiliza) (MACIEL, 1983, p. 22).
}

Por fim, a criação de situações existenciais típicas do grupo com que se quer trabalhar utiliza problemáticas cotidianas do educando e desafios pedagógicos propostos a estes para que ocorra a reflexão sobre o tema gerador, sendo esse o movimento dialógico entre sujeito e o contexto a qual está inserido. Para Freire (2019a), existe uma relação dialética entre indivíduos e os contextos socioeconômico-culturais em um movimento crítico de transformação da realidade a qual o sujeito está inserido. Isso se dilui no ambiente escolar como consequência da reflexão e de maneira concomitante ocorrerá a alfabetização do conteúdo proposto emergido de forma horizontal no diálogo entre educador e educando.

Essa análise de problemas nacionais e regionais se faz com a inserção dos vocábulos geradores, com gradação progressiva, ou seja, partindo daqueles de menor dificuldade fonética para aqueles que têm maior dificuldade. Aqui observamos certamente a característica referente à educação como dialógica, ou seja, realizada através do diálogo com os estudantes sobre problemas do cotidiano e com a inserção dos aspectos que deveriam ser ensinados.

Nesse sentido, os temas geradores são mediadores no processo de produção do conhecimento e emancipação. No modelo tradicional de educação, o bancário, o professor de forma unilateral é o gerador dos temas, tendo como mediação o currículo. Em uma perspectiva freireana, as contradições socioeconômicas e culturais são a mediação entre os sujeitos, educador e educando, visando à leitura crítica do mundo e sua transformação.

Observa-se que a perspectiva de debate pode englobar diversos temas e, por essa razão, podemos concretizar conexões com os conteúdos escolares, em sua grande diversidade. Reside aí a grande aplicação do método de Paulo Freire (2019c) que assim estarão inseridos no contexto social do educando. 


\section{Aspectos epistêmicos e metodológicos da proposta pedagógica freireana}

Ao tecer um conhecimento que objetiva leitura crítica e emancipatória do mundo, Freire (2019c) realizou críticas à concepção de educação vigente em seu tempo que ainda marca a contemporaneidade. A educação bancária contempla uma forma de reprodução do modelo social desigual que retira a humanidade de uma parcela dos seres humanos no ocidente quando determinados temas como pobreza, fome e desemprego são alijados dos debates em sala. Isso acaba contribuindo para formação de indivíduos que irão enxergar essas temáticas como fatalidades e não como realidades construídas e passíveis de serem modificadas, ajudando a reproduzir uma sociedade alienada, acrítica e desigual. Nessa perspectiva, mulher e homem são individualizados e ainda culpabilizados pelas realidades sociais ${ }^{8}$.

Partindo disso, Freire (2019c) defende uma alfabetização para indivíduos que, ao lerem o mundo, compreendam o local comum que ocupam dentro da produção socioeconômica e, a partir da noção de sua historicidade, não sejam comprometidos com a reprodução de um modelo desigual e autoritário de sociedade. Ao contrário, espera-se que lutem por uma educação emancipadora.

É possível observar a defesa de uma educação emancipatória para as camadas populares, uma educação que seja capaz de enxergar além da neblina que inviabiliza a leitura de mundo e a capacidade de compreendê-lo socioeconomicamente como reprodução/construção, passível, portanto, de ser transformada, possuindo a nosso ver cinco pontos epistemológicos fundamentais:

- Primeiro - todo sujeito possui e produz conhecimento. O conhecimento é toda capacidade de modificar e interagir com a dimensão material, ética e estética do mundo, não sendo apenas o instituído no currículo com o respaldo do "é científico". Para Freire (2019a), comumente o que chamam de senso comum é também conhecimento enquanto temporalidade e ação capaz de modificar espacialidades e realidades, advinda disso a compreensão freireana que as próprias camadas populares podem construir seus temas geradores, e, portanto, decodificar e transformar suas realidades;

- Segundo - o conhecimento é uma construção histórica. Todo conhecimento possui uma historicidade, portanto, é construído e legitimado coletivamente. Por ser histórico não é contínuo, pode ser ressignificado ou desconstruído;

- Terceiro - todo conhecimento é um ato político uma vez que mostra o local comum de fala e defesa dos indivíduos que produzem/defendem determinado conhecimento. Cabe questionarmos: a educação que defendemos torna o mundo mais igual ou mais desigual?

- Quarto - a construção do conhecimento envolve também a construção de sentidos e significados culturais. Em outras palavras, a produção de conhecimentos nos leva a interpretar e dar sentidos a fenômenos e problema sociais em um movimento que é subjetivo e coletivo ao mesmo tempo, e por isso, dialético e histórico;

- Quinto - o diálogo feito de forma horizontal é condição sine qua non para educador e educando problematizarem a realidade de forma humanizadora e emancipatória ao se produzir conhecimento.

Nesse sentido, compreendemos que existem três parâmetros político-filosóficos na pedagogia freireana que estão presentes nesses aspectos epistemológicos. Primeiro é a ética como compromisso de humanização a partir do reconhecimento da existência de indivíduos que acordam e dormem sem condições materiais mínimas e a defesa de estratégias de superação dessa situação em busca de uma realidade de mais igualdade do ponto de vista socioeconômico, o que perpassa o acesso à educação e as práticas pedagógicas.

\footnotetext{
${ }^{8}$ Em nossas pesquisas realizadas no PIBIC/2011-2014, ao longo da graduação encontramos mulheres analfabetas e ao solicitarmos para assinarem o Termo de Autorização para Publicação se sentiam envergonhadas e culpadas por não terem aprendido a ler e escrever.
} 
O segundo parâmetro é a criticidade enquanto apreensão do contexto da realidade social e econômica vigente visando à construção de novas realidades que busquem a transformação e emancipação de sujeitos. O aspecto ético e crítico se dilui em um terceiro parâmetro: a dimensão dialógica enquanto práxis que mobiliza o anúncio da existência de desigualdades e tensões que objetivam sua superação na busca da emancipação.

\section{Correlações entre pesquisa-ação e práxis pedagógica freireana}

Considerando o conceito, as implicações e a relação do pesquisador com o campo de pesquisa acerca da pesquisa-ação, seguiremos o raciocínio e buscaremos a correlação com o método de Paulo Freire, e a práxis pedagógica freireana correlacionada ao envolvimento bidimensional entre atores sociais com vistas à resolução, isso é um problema social característico da pesquisa-ação.

De acordo com Freire (2019b) podemos compreender a práxis como ação que está direcionada por uma orientação teórica. Podemos entendê-las como complementares, não duais, em que teoria e prática são componentes de um mesmo objeto, na tentativa de mobilizar a transformação de um dado problema social. Nesse sentido, a dimensão teórica não se separa da realidade social construída historicamente e culturalmente estabelecida.

Nenhuma dimensão teórica faz sentido se não está direcionada à dimensão prática da vida de indivíduos que através do diálogo horizontal procuram problematizar sua realidade. Esse diálogo é elemento principal da prática pedagógica libertadora, necessário não somente ao docente que pratica este pensamento, mas também aos que querem construir um pensamento mais imbricado na realidade do educando.

Quando muito jovem eu fui aos mangues do Recife, aos morros de Recife e ao trabalhar com os camponeses, chegando lá me deparei com a realidade dura desses grupos onde seu ser é negado como gente. Não foram os camponeses que pediram para eu ler Marx, foi a realidade deles que me remeteu a ler Marx (FREIRE, 1994, s.p.).

Nesse sentido, para Paulo Freire (1994) a ação e reflexão se complementam quando grupos sociais procuram uma educação problematizadora da realidade dada e procuram superar situações de autoritarismos, desigualdades e violências, em que a condição de humanidade de seres humanos é suprimida em nome de interesses de grupos políticos/econômicos por conta da materialidade no mundo da reprodução do capital.

Pensamos que esses caminhos são fundamentais enquanto posições epistemológicas na pesquisa-ação em programas de educação profissional. A proposta de se pensar e intervir na educação básica deve "caminhar" ao lado da ideia de que uma criança ou um jovem são indivíduos dotados de inacabamento característico de todas as espécies que habitam esse planeta. Homens e mulheres, porém, possuem e compartilham cultura, pois, sabem que são seres inacabados e, então, assumem processos formativos que possibilitam caminhar, dialogar, interagir e modificar o mundo.

Essa condição de inacabamento dá a possibilidade de rever práticas e aprofundar conhecimentos, características também levantadas por Freire (2019b) dentro de sua proposta pedagógica que chama a atenção enquanto ponto de correlação com a pesquisa-ação.

Freire (2019c) formulou uma relação de movimento entre a tomada de consciência e a atividade sobre o real. Em outras palavras, propôs um movimento entre teoria e a prática, tendo como fim pensar, problematizar e modificar problemáticas sociais a partir da práxis. Dessa forma, embora não estivesse utilizando o termo pesquisa-ação em suas obras, entende-se que esse movimento, presente na proposta pedagógica de Freire, possui forte correlação com os 
pressupostos da pesquisa-ação, tomados neste trabalho a partir de (THIOLLENT, 1986; BARBIER, 2004).

Nesse sentido, perceber a pesquisa em educação a partir da pesquisa-ação em programas de pós-graduação em educação profissional, que possuem o caráter de investigação aplicada enquanto ato cooperativo entre sujeitos, a partir de Paulo Freire (2019c), é entender que o pensamento teórico tem uma relação dialética entre a ação orientada pela teoria e a experiência concreta dos sujeitos do processo de ensino e aprendizagem na escola. É entender também que na pesquisa-ação participam do movimento da pesquisa, da construção do conhecimento e não apenas no preenchimento de formulários ou cessão de suas experiências a partir de sua oralidade, para que um dito intelectual acadêmico possa interpretá-las à luz do seu referencial teórico.

Essa interpretação ocorre na pesquisa-ação, mas de forma integrada e dialógica, no corpo a corpo do encontro com o outro em uma via de mão dupla. Dessa forma, compreendese que a pesquisa-ação procura ao máximo não criar hierarquizações no processo de produção de conhecimento. Pesquisa-ação, assim como a proposta pedagógica freireana, da práxis pedagógica requer empatia, reciprocidade, encontros, alteridade e diálogo.

Nesse sentido, compreende-se que Freire (2019b) dialoga com a metodologia da pesquisa-ação quando estabelece uma relação dialógica entre atividade da consciência e atividade sobre o real, dito de outro jeito, entre teoria e prática conectadas com o objetivo de promover a afirmação da práxis.

É no despertar da consciência que o sujeito aprende ler o local comum que ocupa no mundo. É nesse aspecto que observamos a aplicação da leitura de mundo antes da leitura da palavra, em que, de igual maneira, observamos a possibilidade de construção de conhecimento sendo realizada antes da aprendizagem escolar, tal como observamos em Vigotski (2019), essa visão possibilita a tomada de decisão na intervenção e modificação da realidade do discente. Toda realidade está posta e pode sofrer intervenção quando se assume que os sujeitos dotados de uma historicidade, consequentemente, realizam esse movimento consciente.

Por conta disso, compreende-se que a pesquisa-ação possui correlação direta com os movimentos sociais, com os grupos à margem dessa sociedade de renda e consumo, massas de pessoas em sua maioria desempregadas ou no mercado informal, quando no campo sem-terra, produzidos proposital e assertivamente pelo sistema econômico com o intuito de manter as relações entre capital, remuneração e trabalho.

A pesquisa-ação é uma atividade de compreensão e de explicação da práxis dos grupos sociais por eles mesmos, com ou sem especialistas em ciências humanas e sociais práticas, com o fito de melhorar sua práxis, ou seja, com o intuito de transformar sua conduta no uso de uma ação transformadora (BARBIER, 2004, p. $67)$.

A pesquisa-ação e a práxis pedagógica freireana se tornam uma possibilidade de movimento entre objetivos de conhecimento e objetivos de ação na proposta de pesquisa-ação; em que temas de questões qualitativas são abordados a partir de um dado referencial teóricometodológico e mantêm diálogo direto e constante com ação, sempre com vistas à resolução de um problema social, ou seja, a pesquisa voltada para construção de conhecimentos em cooperação de grupos de modo horizontal e bilateral.

\section{Considerações finais}

A pesquisa-ação surge de uma ruptura epistemológica na construção do conhecimento em ciências humanas em contraposição à pesquisa tradicional. Esta metodologia privilegia mais a experiência dos sujeitos do que quadros teóricos. 
Reside nesse aspecto, a correlação discutida neste manuscrito entre pesquisa-ação e práxis pedagógica freireana, na qual a estratégia para superação de uma dada problemática social envolve determinados atores em um diálogo em que subjetividade e historicidade são problematizadas em um movimento que enseja transformação da realidade em um caminho de igualdade, liberdade, diálogo, alteridade na afirmação da condição de humanos em busca de cidadania.

A visão e a relação do pesquisador sobre o público pesquisado é parte principal para a convergência do método de pesquisa-ação e o método de ensino de Paulo Freire. Ambos consideram a visão desse autor sobre o mundo em que habita e transforma, sendo a parte integrante para uma prática que visa à transformação social do imbricado na pesquisa.

Ao situarmos a pesquisa-ação como método de pesquisa, observamos a posição abrangente dessa ferramenta no contexto acadêmico, sendo primordial para as investigações em ciências sociais. Ao identificá-la com o método de ensino do Paulo Freire, observamos a amplitude de aplicações dentro do contexto educacional e a convergência de ambos no sentido de conservar a participação das minorias na modificação do meio de vivência e da sociedade como um todo, da tomada de consciência para a resolução de um problema e para a dialogicidade sobre as mazelas sociais do lócus.

A convergência dos pensamentos praticados na metodologia de pesquisa-ação e de Paulo Freire é reforçada pela ação destinada a atender especificidades daqueles que por muito tempo foram explorados e oprimidos, o que reforça a necessidade de lutar, seja por meio da educação, seja por meio da pesquisa.

\section{Referências}

BARBIER, René. A pesquisa-ação. Local: Liber Livro, 2004.

BRANDÃO, Carlos Rodrigues. O que é método de Paulo Freire. 1. ed. São Paulo: Editora Brasiliense. 1981.

CANDAU, Vera Maria. Multiculturalismo e Educação: desafios para a prática pedagógica. In: MOREIRA, Antonio Flávio; CANDAU, Vera Maria. Multiculturalismo: diferenças culturais e práticas pedagógicas. Petrópolis: Vozes, 2008.

FREIRE, Paulo. Educação como prática da liberdade. 45. ed. São Paulo: Paz e Terra, 2019a.

FREIRE, Paulo. Pedagogia da autonomia: saberes necessários à prática educativa. São Paulo: Paz e Terra, 2019b.

FREIRE, Paulo. Pedagogia do oprimido. 71. ed., São: Paz e Terra, 2019c.

FREIRE, Paulo. Política e Educação. 5. ed. São Paulo: Paz e Terra, 2020.

FREIRE, Paulo. PROF. Paulo Freire. São Paulo: USP - Cdcc, 1994. P\&B. Disponível em: https://www.youtube.com/watch?v=2C518zxDAo0. Acesso em: 14 jan. 2021.

FREIRE, Paulo. A alfabetização de adultos: é ela um que fazer neutro? Revista Educação e Sociedade, UNICAMP / Cortez \& Moraes, v. I, n. 1, set. 1978.

LUDKE, Menga; ANDRÉ, Marli E. D. A. Pesquisa em educação: abordagens qualitativas. Rio de Janeiro: RJ, E. P. U., 2020. 
LUNA, Sérgio Vasconcelos de. Planejamento de pesquisa: uma introdução. 2. ed. São Paulo: EDUC, 2011.

MACIEL, Jarbas, Fundamentação teórica do Sistema Paulo Freire de Educação. In FÁVERO, O. (Org.). Cultura popular, educação popular: memória dos anos 60. Rio de Janeiro: Graal, 1983.

OLIVEIRA, Maria Marly de. Como fazer pesquisa qualitativa. 7. ed. Petrópolis:Vozes,2016.

THIOLLENT, Michael; Metodologia da pesquisa-ação. 2. ed. Cortez: São Paulo, 1986.

VIGOTSKY, Lev Semenovich. A construção do pensamento e da linguagem. Trad. Paulo Bezerra. 2. ed. São Paulo: WMF Martins Fontes, 2019. 